\title{
The Conformance of Urine PH with Tongue Rolling
}

\author{
Muhammad Imran Qadir ${ }^{1}$, Muhammad Asad $\mathbf{A l i}^{2 *}$ \\ Institute of Molecular Biology and Biotechnology, Bahauddin Zakariya University, Multan, Pakistan
}

*Corresponding Author: Muhammad Asad Ali, Institute of Molecular Biology and Biotechnology, Bahauddin Zakariya University, Multan, Pakistan.

\begin{abstract}
As with density, there are typical but not "abnormal" waste proton concentration values. The urine is typically slightly acidic, about $\mathrm{pH}$ 6, but can vary from four.5-8. The kidneys play a really necessary role in maintaining the equilibrium of the body. The study on tongue rolling Reincynomolgus monkey shown that the motor nerves of the medial division of hypoglossol neucleus are connected with the tongue muscles orientated them in crosswise plane to the long axis of tongue and also the motor neurons of lateral division are innervated with tongue muscles orienting them parallel to the long axis of tongue. Researchers claimed that the tongue rolling as morphological character isn't controlled genetically however learned. As per given resultant values in table below the female rollers, male non rollers and female non-rollers have shown significant values. It predicts that there is some conformance of urine PH with tongue rolling.
\end{abstract}

Keywords: Vigna subterranea, Rhizobia, native strain, nodules, agronomic characters

\section{INTRODUCTION}

As with density, there are typical but not "abnormal" waste proton concentration values. The urine is typically slightly acidic, about $\mathrm{pH} 6$, but can vary from four.5-8. The kidneys play a really necessary role in maintaining the equilibrium of the body. Therefore, any condition that produces acids or bases at intervals the body, like pathology or pathology, or the uptake of acidic or basic foods can directly have a sway on waste proton concentration.

Tongue is that the extremely muscular organ of the speech style and drink. Tongue rolling is that the movement of tongue in shape and may be a morphological attribute. The system is connected with the tongue via the hypoglossal. It's still below analysis that however the motor neurons innervate the intrinsic muscles of the tongue and management the movement of tongue whereas turning it in shape. The study on tongue rolling Reincynomolgus monkey shown that the motor nerves of the medial division of hypoglossol nucleus are connected with the tongue muscles orientated them in crosswise plane to the long axis of tongue and also the motor neurons of lateral division are innervated with tongue muscles orienting them parallel to the long axis of tongue. Researchers claimed that the tongue rolling as morphological character isn't controlled genetically however learned.

\section{MATERials AND Methods}

Urine analysis was performed by screening methodology. A strip mentioned as piss check strip was used. Samples were collected below healthful conditions in sterilized disposable containers. Samples were born at the workplace and analysis was performed. By dipping the strip into the piss nearly for thirty seconds and once drying the strip resultant values were noted by matching the color variation among the strip bands.

\subsection{Project Designing}

Total eighty material samples were collected and waste analysis was performed. The sample donors were the students of Institute of biology and Biotechnology, Bahauddin Zakariya University Multan, Pakistan.

\subsection{Statistical Analysis}

Statistical analyses were performed by applying MS stand out. Share was counted and results were predicted on the basis of that share count. 


\section{RESULTS AND DISCUSSION}

TABLE1. URINE $P H$

\begin{tabular}{|c|c|c|}
\hline Tongue Rolling & Urine PH & $\boldsymbol{p}$-value \\
\hline Male Rollers & $6.00 \pm 0.00$ & 0.16 \\
\hline Female Rollers & $6.08 \pm 0.27$ & $0.05^{*}$ \\
\hline Male non- Rollers & $0.00 \pm 0.00$ & $0.00^{*}$ \\
\hline Female non-Rollers & $6.46 \pm 0.99$ & $0.01^{*}$ \\
\hline
\end{tabular}

As per given resultant values in above table the female rollers, male non rollers and female non-rollers have shown significant values. It predicts that there is some conformance of urine $\mathrm{PH}$ with tongue rolling. Male rollers have urine $\mathrm{PH}$ range between $6.00 \pm 0.00$, female rollers have $6.08 \pm 0.27$ while male non-rollers have $0.00 \pm 0.00$ and female non-rollers have $6.46 \pm 0.99$.

\section{CONCLuSion}

As per given resultant values in above table the female rollers, male non rollers and female non-rollers have shown significant values. It predicts that there is some conformance of urine $\mathrm{PH}$ with tongue rolling.

\section{REFERENCES}

[1] Qadir MI, Noor A (2018) Anemias. Rare \& Uncommon Diseases. Cambridge Scholars Publishing. Newcastle, England. ISBN: 978-1-5275-1807-0.

[2] Qadir MI, Javid A (2018) Awareness about Crohn's Disease in biotechnology students. Glo Adv Res J Med Medical Sci, 7(3): 062-064.

[3] Qadir MI, Saleem A (2018) Awareness about ischemic heart disease in university biotechnology students. Glo Adv Res J Med Medical Sci, 7(3): 059-061.

[4] Qadir MI, Ishfaq S (2018) Awareness about hypertension in biology students. Int J Mod Pharma Res, 7(2): 08-10.

[5] Qadir MI, Mehwish (2018) Awareness about psoriasis disease. Int J Mod Pharma Res, 7(2): 17-18.

[6] Qadir MI, Shahzad R (2018) Awareness about obesity in postgraduate students of biotechnology. Int J Mod Pharma Res, 7(2): 14-16.

[7] Qadir MI, Rizvi M (2018) Awareness about thalassemia in post graduate students. MOJ Lymphology \& Phlebology, 2(1): 14-16.

[8] Qadir MI, Ghalia BA (2018) Awareness survey about colorectal cancer in students of M. Phil Biotechnology at Bahauddin Zakariya University, Multan, Pakistan. Nov Appro in Can Study, 1(3): NACS.000514.2018.

[9] Qadir MI, Saba G (2018) Awareness about intestinal cancer in university student. Nov Appro in Can Study, 1(3): NACS.000515.2018.

Citation: Muhammad Imran Qadir \& Muhammad Asad Ali, " The Conformance of Urine PH with Tongue Rolling", International Journal of Research Studies in Microbiology and Biotechnology (IJRSMB), vol. 5, no. 3, pp. 1-2, 2019. Available: DOI: http://dx.doi.org/ 10.20431/2454-9428.0503001

Copyright: (1) 2019 Authors. This is an open-access article distributed under the terms of the Creative Commons Attribution License, which permits unrestricted use, distribution, and reproduction in any medium, provided the original author and source are credited. 